\title{
White Matter Plasticity and Enhanced Remyelination in the Maternal CNS
}

\author{
Christopher Gregg, Viktor Shikar, Peter Larsen, Gloria Mak, Andrew Chojnacki, V. Wee Yong, and Samuel Weiss \\ Hotchkiss Brain Institute, Departments of Cell Biology, and Anatomy and Clinical Neurosciences, Faculty of Medicine, University of Calgary, Calgary, \\ Alberta, Canada T2N 4N1
}

\begin{abstract}
Myelination, the process in which oligodendrocytes coat CNS axons with a myelin sheath, represents an important but poorly understood form of neural plasticity that may be sexually dimorphic in the adult CNS. Remission of multiple sclerosis during pregnancy led us to hypothesize that remyelination is enhanced in the maternal brain. Here we report an increase in the generation of myelin-forming oligodendrocytes and in the number of myelinated axons in the maternal murine CNS. Remarkably, pregnant mice have an enhanced ability to remyelinate white matter lesions. The hormone prolactin regulates oligodendrocyte precursor proliferation and mimics the regenerative effects of pregnancy. This suggests that maternal white matter plasticity imparts a striking ability to repair demyelination and identifies prolactin as a potential therapeutic agent.
\end{abstract}

Key words: remyelination; pregnancy; oligodendrocyte; proliferation; maternal; multiple sclerosis

\section{Introduction}

Oligodendrocytes, the myelinating cells of the CNS, continue to be generated by oligodendrocyte precursor cells (OPCs) throughout adulthood within both the rodent (Gensert and Goldman, 1997; Levison et al., 1999; Menn et al., 2006) and primate (Peters and Sethares, 2004) CNS. The process of myelination represents a major form of plasticity in the developing and adult CNS and is postulated to influence neuronal health, conductance velocity, and the synchronicity of spike time arrival, thus enhancing CNS function (Dong and Greenough, 2004; Fields, 2005). Furthermore, OPCs and newly generated oligodendrocytes are required for the intrinsic repair of myelin damage in the adult CNS (Polito and Reynolds, 2005). However, other than the response to injury, physiological changes that modify OPC proliferation and the generation of new myelinating oligodendrocytes in the adult CNS are not known.

Studies of plasticity in the adult brain at the level of cell genesis have primarily focused on hippocampal and olfactory neurogenesis (Lledo et al., 2006). We previously observed a female-specific form of plasticity in which olfactory neurogenesis, but not hippocampal neurogenesis, increases in the maternal forebrain during the first week of pregnancy in response to the hormone prolactin (PRL) (Shingo et al., 2003). Interestingly, recent studies

\footnotetext{
Received Aug. 24, 2006; revised Jan. 4, 2007; accepted Jan. 10, 2007.

This work was supported by the Canadian Institutes of Health Research (S.W.) and the Multiple Sclerosis Society of Canada (V.W.Y. and S.W.). C.G. and G.M. were supported by Alberta Heritage Foundation for Medical Research (AHFMR) and Stem Cell Network studentships, respectively. V.W.Y. and S.W. are AHFMRScientists. We acknowledge excellent technical support from Sharmin Chowdry, Rozina Hassam, Yan Fan, as well as Wei-Xiang Dong of the University of Calgary Microscopy and Imaging Facility. We thank Drs. Quentin Pittman, Ken Lukowiak, Cindi Morshead, Derek van der Kooy, and Samuel Ludwin for critically reviewing a previous version of this manuscript, as well as Kathryn Markham and Brent Kuzmiski for help with experiments.

Correspondence should be addressed to Samuel Weiss, 2263, 3330 Hospital Drive NW, Calgary, Alberta, Canada T2N 4N1. E-mail: weiss@ucalgary.ca.

D0I:10.1523/JNEUROSCI.4441-06.2007

Copyright $\odot 2007$ Society for Neuroscience $\quad$ 0270-6474/07/271812-12\$15.00/0
}

indicate structural and functional gender differences in the white matter of the CNS (Gur et al., 1999; Allen et al., 2003; Haier et al., 2005), suggesting that the generation of new oligodendrocytes during adulthood might be closely linked to sexually dimorphic physiology and behavior, such as maternity. In rodents, females, relative to males, have a higher proportion of unmyelinated axons in the corpus callosum (CC) (Mack et al., 1995; Kim and Juraska, 1997) and greater oligodendrocyte turnover during adulthood (Cerghet et al., 2006). Multiple sclerosis (MS), a demyelinating disease more common to females than males, undergoes remission during pregnancy (Confavreux et al., 1998; Voskuhl, 2003), and this is correlated with a decrease in the number and size of active white matter lesions (van Walderveen et al., 1994). Thus, we hypothesized that pregnancy promotes increases in OPC proliferation, which bestows an enhanced capacity to generate oligodendrocytes and regenerate myelin in the maternal CNS.

In the present study, we find that pregnancy results in an increase in the generation of new oligodendrocytes and the number of myelinated axons within the maternal CNS. Pregnancyinduced white matter changes were associated with an enhanced capacity to repair myelin damage in the maternal CNS. Furthermore, prolactin signaling regulated OPC proliferation during pregnancy and was found to be sufficient to promote white matter repair in virgin mice. These results reveal the first adaptive regulatory mechanism for oligodendrocyte generation in the adult CNS, identify prolactin as a potential therapeutic agent for promoting white matter repair, and suggest a novel factor that may contribute to the remission of MS during late stages of pregnancy.

\section{Materials and Methods}

Animals

Female 6- to 8-week-old CD-1 virgin mice (Charles River Canada, Laval, Quebec, Canada) were used in breeding [day of vaginal plug was desig- 
nated gestational day 0 (GD0)] or infusion experiments. Prolactin receptor $(\mathrm{Prlr})^{+/+}$and $\mathrm{Prlr}^{+/-}$females (originally obtained from The Jackson Laboratory, Bar Harbor, ME) were mated with wild-type males and separated on the day that a vaginal plug was detected. Genotyping was performed by PCR as described previously (Ormandy et al., 1997; Shingo et al., 2003). Animals were maintained on a $12 \mathrm{~h}$ light/dark cycle with food and water ad libitum, were allowed to survive as described, and were then killed, and the tissue was processed as described below.

\section{Prolactin infusions}

Female 6- to 8-week-old CD-1 mice were anesthetized with sodium pentobarbital (120 mg/kg, i.p.) and implanted with an osmotic pump (Alzeet 1007D; Alza, Palo Alto, CA), placed subcutaneously, dorsally, between the shoulder blades. Prolactin (mouse recombinant; National Hormone and Peptide Program, Torrance, CA) was dissolved in $0.9 \%$ saline containing $1 \mathrm{mg} / \mathrm{ml}$ mouse serum albumin (Sigma, St. Louis, MO) for delivery at a rate of $16 \mu \mathrm{g} / \mathrm{d}$ for $2.5 \mathrm{~d}$. For intraperitoneal injections, PRL was delivered at a dose of $20 \mu \mathrm{g} /$ injection.

\section{Bromodeoxyuridine labeling}

At various gestational periods or after $2 \mathrm{~d}$ of subcutaneous prolactin infusions, mice were injected with bromodeoxyuridine (BrdU) (Sigma) $(120 \mathrm{mg} / \mathrm{kg}$, i.p., dissolved in $0.007 \% \mathrm{NaOH}$ in phosphate buffer) every $2 \mathrm{~h}$ for $10 \mathrm{~h}$ and killed $0.5 \mathrm{~h}$ (or longer) after the last injection. Animals were killed, and brains, optic nerves (ONs), and spinal cords (SC) (region from approximately C7 to T4) were dissected out and processed for immunohistochemistry as described below. To trace the fate of BrdUpositive $\left(\mathrm{BrdU}^{+}\right)$cells in the $\mathrm{CNS}$, the $\mathrm{BrdU}$ was administered as above to virgin, pregnant, or infused animals on the days indicated in the text, and the animals were left to survive until the appropriate day of analysis (as indicated in text).

\section{Immunohistochemistry}

Animals were killed by anesthetic overdose and perfused transcardially with $4 \%$ paraformaldehyde in PBS, $\mathrm{pH}$ 7.2. Brains, optic nerves, and spinal cords (region from approximately $\mathrm{C} 7$ to $\mathrm{T} 4$ ) were postfixed in the perfusing solution overnight at $4^{\circ} \mathrm{C}$, then cryoprotected for at least $24 \mathrm{~h}$ in 20\% sucrose in PBS, and then embedded in Tissue Tek O.C.T. compound (Sakura Finetek, Torrance, CA) before they were cryosectioned at $14 \mu \mathrm{m}$. Before immunohistochemistry, sections were postfixed with acetone for $30 \mathrm{~s}$ at room temperature and then washed with PBS. For BrdU staining, tissues were treated with $1 \mathrm{M} \mathrm{HCl}$ for $30 \mathrm{~min}$ at $60^{\circ} \mathrm{C}$ to denature cellular DNA. For glutathione $S$-transferase- $\pi$ (GST) $\pi$ staining, sections were microwaved on high for $1.5 \mathrm{~min}$ in $0.01 \mathrm{M}$ citrate buffer, $\mathrm{pH}$ 6.0. The following primary antibodies were used: rat monoclonal anti-BrdU (1: 50; Harlan Seralab, Loughborough, UK), goat anti-platelet-derived growth factor receptor $\alpha$ (PDGFR $\alpha)$ (1:10; R \& D Systems, Minneapolis, $\mathrm{MN}$ ), mouse anti-GST $\pi$ (1:50; BD Biosciences PharMingen, San Diego, $\mathrm{CA}$ ), guinea pig anti-NG2 (gift from William Stallcup, Burnham Institute, La Jolla, CA), rabbit anti-prolactin receptor (1:100; Santa Cruz Biotechnology, Santa Cruz, CA), and rabbit anti-myelin basic protein (MBP) (1:100; DakoCytomation, Carpinteria, CA). Sections were incubated for $24 \mathrm{~h}$ at room temperature in primary antibody diluted in $0.3 \%$ Triton X-100/PBS containing normal goat serum (NGS), washed with PBS, and then incubated with donkey FITC-, cyanine 5 (Cy5)-, or biotinconjugated secondary antibodies (all used at 1:200; Jackson ImmunoResearch, West Grove, PA) for $1 \mathrm{~h}$ at room temperature, followed by incubation with streptavidin-Cy3 (1:2000; Jackson ImmunoResearch) for $1 \mathrm{~h}$ at room temperature, together with Hoechst $33258(0.015 \mathrm{mg} / \mathrm{ml}$ stock solution diluted to $0.001 \mathrm{mg} / \mathrm{ml}$; Sigma). After rinsing with water, sections were mounted with Fluorosave and viewed or photographed with a Zeiss (Oberkochen, Germany) Axiophot fluorescence microscope.

\section{Immunohistochemistry quantification}

Corpus callosum. Two series of coronal sections (14 $\mu \mathrm{m})$ were cut and distributed across seven slides per series (a rostral series of seven slides and a more caudal series of seven slides). We placed 12 sections per slide, each section on a single slide therefore being $\sim 100 \mu \mathrm{m}$ apart $(14 \mu \mathrm{m} \times 7)$ from slides from the next. Serial sections were collected beginning from the first appearance of the rostral tip of the corpus callosum. Quantifica- tion of immunoreactive cells in the CC occurred in 12 sections that were identified across one slide from the first series (rostral sections) and one from the second series (caudal sections). Counting was performed beginning caudally and was landmarked by beginning with the section at which the lateral ventricles first join at the third ventricle (midbody of the CC) and included this section and the 11 sections rostral to it (up to caudal region of the genu located above the lateral ventricles). Counts included the entire lateral and medial regions (tip to midline) of the CC in both hemispheres of the brain in the sections.

Spinal cord. Two series of coronal sections $(14 \mu \mathrm{m})$ were cut starting at C7 with seven slides per series and 12 sections per slide. All 12 sections were counted from one slide in the second series, which corresponded to the $\mathrm{T} 2$ region.

Optic nerve. Two series of coronal sections $(14 \mu \mathrm{m})$ were cut starting from the end of the ON furthest from the eye with seven slides per series and 12 sections per slide, and all 12 sections were counted from one slide in the second series. When counting the total number of PDGFR $\alpha^{+}$cells in the CC, SC, and ON, we checked each cell for the presence of a Hoechst ${ }^{+}$nucleus that was surrounded by PDGFR $\alpha$. Values within the manuscript represent the total number of positive cells counted in 12 sections unless otherwise stated.

\section{Oligodendrocyte process and MBP expression quantification}

Oligodendrocytes in virgin or pregnant mice were identified by GST $\pi$ immunoreactivity. New oligodendrocytes in GD7-GD18, GD7 to postpartum day 7 (P7), and GD7-P14 BrdU trace experiments were identified by coexpression of BrdU and GST $\pi$. Cells were randomly selected in the corpus callosum for imaging. Confocal $z$-stacks encompassing the entire soma and processes were acquired with a Olympus Optical (Tokyo, Japan) Fluoview BX-50 laser scanning confocal microscope for a minimum of 25 cells for each animal. The $z$-stacks were rendered into a three-dimensional (3-D) rotating video using Fluoview Software, and the number of GST $\pi^{+}$processes extending clearly from the soma was quantified for each cell. The representative 3-D images of oligodendrocytes presented in the manuscript were rendered into a 3-D format using Imaris Software (Bitplane, Minneapolis, MN). To determine whether newly generated oligodendrocytes express MBP, sections were triple labeled for BrdU (FITC), GST $\pi$ (rhodamine), and MBP (Cy5). Cells in the corpus callosum that coexpressed BrdU and GST $\pi$ were randomly selected for confocal imaging on the basis of the expression of these two markers alone (minimum of 25 cells per animal). Confocal $z$-stacks were taken that encompassed the cell and visible processes using the FITC, rhodamine, and Cy5 channels. Analysis of the $z$-stacks using Fluoview Software was used to confirm the presence or absence of any MBP expression within the cell body and/or processes, and the percentage of $\mathrm{MBP}^{+}$newly generated oligodendrocytes was determined.

\section{Western blotting}

The CC was dissected from the forebrain (see below, Adult oligodendrocyte precursor cell culture), and a $2 \mathrm{~mm}$ segment of the upper thoracic SC (approximately T1-T3) was removed, as well as the ovaries. The tissue was transferred to radioimmunoprecipitation assay (RIPA) buffer [50 mu Tris-HCl, pH 7.4, 1\% NP-40, 0.25\% Na-deoxycholate, $150 \mathrm{~mm} \mathrm{NaCl}$, $1 \mathrm{~mm}$ EDTA, 1 mм PMSF, $1 \mathrm{~mm} \mathrm{Na} \mathrm{VO}_{4}, 1 \mathrm{~mm} \mathrm{NaF}$, and 1 Protease Inhibitor Cocktail Tablet (Roche, Manheim, Germany) per $7 \mathrm{ml}$ of RIPA] and homogenized for protein extraction. In each experiment, 15 $\mu \mathrm{g}$ of protein was fractionated by $10 \%$ SDS-PAGE and transferred to nitrocellulose membranes (Bio-Rad, Hercules, CA). The membranes were blocked in blocking buffer ( $25 \mathrm{~mm}$ Tris- $\mathrm{HCl}, \mathrm{pH} 7.5,0.5 \mathrm{M} \mathrm{NaCl}$, $0.3 \%$ Tween 20 , and $5 \%$ nonfat skim milk) and incubated with the following primary antibodies overnight at $4^{\circ} \mathrm{C}$ (final concentration): rabbit anti-MBP (1:10,000), rabbit anti-PRLR (1:100; sc-20992; Santa Cruz Biotechnology, Santa Cruz, CA), and rabbit anti-actin (1:1000; Abcam, Cambridge, MA). Blots were washed and probed with the appropriate peroxidase-conjugated secondary antibodies (1:5000; Jackson ImmunoResearch). Immunoreactivity was developed by enhanced chemiluminescence (Amersham Biosciences, Arlington Heights, IL). The protein levels were quantified by first measuring the average intensity of the individual bands using Eastman Kodak (Rochester, NY) 1D 3.6.2 soft- 
ware. The average intensity was multiplied by the area of the band, calculated by measuring band size with NIH ImageJ software, to give a value representative of protein expression levels. MBP protein levels were normalized to actin to control for differences in protein loading. The murine PRLR long form (PRLR-L) protein bands were recognized in the molecular weight range previously described by others (Ling et al., 2000; Camarillo et al., 2001).

\section{Reverse transcription-PCR}

The CC, SC, and ovaries were dissected from adult virgin female mice. RNA was isolated using a QIAshredder and Qiagen RNeasy kit (Qiagen Mississauga, Ontario, Canada). RNA was reverse transcribed using oligo-dT primers from the SuperScript III First-strand Synthesis System for reverse transcription (RT)-PCR (Invitrogen, Carlsbad, CA). Previously published methods and primers specific for the PRLR-L, PRLR short form 1 (PRLR-S1), PRLR-S2, and PRLR-S3 were used to amplify cDNA (Ling et al., 2000). Separation on an agarose gel and sequencing confirmed the specificity of the primers for the amplification of a $254 \mathrm{bp}$ product that corresponded to the appropriate PRLR isoform.

\section{Lysolecithin demyelinating lesions and lesion size index}

Lesions were performed and quantified as described previously (Larsen et al., 2003). Briefly, mice were anesthetized with a mixture of ketamine $(200 \mathrm{mg} / \mathrm{kg})$ and xylazine $(10 \mathrm{mg} / \mathrm{kg})$, and the spinal cord was then exposed. A $1.5 \mu$ l solution of 1\% D-lysophosphatidylcholine (lysolecithin; Sigma) was injected slowly $(0.5 \mu \mathrm{l} / \mathrm{min})$ into the dorsal funiculus at the T3-T4 level using a 33 gauge needle attached to a $5 \mu$ l Hamilton syringe. The needle was left for an additional $2 \mathrm{~min}$ to avoid backflow of the lysolecithin. Mice were allowed to recover for defined periods as described, after which they were killed and the spinal cord was removed. For histological characterization of lesions, the spinal cord was fixed in $10 \%$ buffered Formalin. One millimeter blocks covering $2 \mathrm{~mm}$ on either side of the lesion were embedded in paraffin, and $10 \mu \mathrm{m}$ sections were cut at $100 \mu \mathrm{m}$ intervals (thus, 10 sections per millimeter block were analyzed). Sections were stained for myelin using Luxol fast blue (Solvent blue 38; Sigma). Briefly, sections were deparaffinized, incubated in the solvent blue solution for $3 \mathrm{~h}$ at $60^{\circ} \mathrm{C}$, destained with $0.05 \%$ lithium carbonate, and counterstained with hematoxylin/eosin. The demyelinated lesion area in the dorsal funiculus and the total area of the dorsal funiculus of each section was calculated using NIH ImageJ software for a total of 36 sections per animal. The border between the myelinated and unmyelinated regions of the dorsal funiculus were clearly defined by a border of dark blue staining. The ratio of lesion area to total dorsal funiculus area for each section was summed for all 36 sections to provide an index of the proportion of the dorsal funiculus that was demyelinated (referred to as the lesion size index in Results).

\section{Lysolecithin demyelinating lesions and BrdU tracing}

Six- to 8-week-old female mice received lysolecithin lesions as described above (for pregnancy study summary, see Fig. $3 b$ ). Pregnant females received lesions on GD3 and then received five BrdU injections over $8 \mathrm{~h}$ on GD4, GD5, GD6, and GD7. Pregnant and matched virgins were left to trace the fate of the BrdU-labeled cells for $7 \mathrm{~d}$ and were then killed and perfused with $4 \%$ paraformaldehyde. A $2 \mathrm{~mm}$ segment of the spinal cord that contained the lysolecithin injection site in the center was removed and processed for cryosectioning at a thickness of $14 \mu \mathrm{m}$. The entire 2 $\mathrm{mm}$ segment was sectioned serially in two series of seven slides. One slide was selected from each series for each animal, and the total number of $\mathrm{BrdU}^{+} \mathrm{GST} \pi^{+}$cells in the lesioned dorsal funiculus was quantified for every section. To study the effects of PRL treatment on the generation of new oligodendrocytes after lesion, animals received lesions followed by daily injections of $20 \mu \mathrm{g}$ of PRL or vehicle control (VEH) on days 1 through 7 and BrdU on days 4, 5, 6, and 7 and were analyzed as above on postlesion day 14 .

\section{Electron microscopy analysis and quantification}

Postpartum day 14 mothers and age-matched virgins were transcardially perfused with $4 \%$ paraformaldehyde, and the brain was removed. The entire brain was immersion fixed in $2.5 \%$ glutaraldehyde for $2 \mathrm{~d}$ and then cut in half sagittally down the sagittal suture. A $1 \mathrm{~mm}$ sagittal slab was then cut from the midpoint of the brain that clearly included the CC. This region was further trimmed under a microscope to attain the genu region of the CC, which was immersed in $2.5 \%$ glutaraldehyde for $2 \mathrm{~d}$ and then processed for embedding in plastic. Semithin cross sections of the genu were stained with toluidine blue, and the same rostral region of the genu was selected for electron microscopy (EM) analysis in each animal. EM sections were photographed, 20 random fields per animal, and the number of myelinated axons per $100 \mu \mathrm{m}$ was quantified on a computer screen. Lysolecithin lesioned virgin and pregnant mice were transcardially perfused with $4 \%$ paraformaldehyde, and the entire spinal cord was removed. A single $1 \mathrm{~mm}$ section of the lesioned spinal cord that included the injection site positioned in the center of the section was dissected from the spinal cord. Semithin cross sections of the spinal cord were stained with toluidine blue, and the lesioned area of the dorsal funiculus was visualized by light microscopy. An area within the mid-upper portion of the dorsal funiculus, within the center of the lesion, was chosen for analysis and processed for visualization by EM. The lesioned area was photographed under EM and spared, remyelinated, and demyelinated axons were later quantified on a computer screen. This approach resulted in the analysis of an average of $\sim 800$ axons per animal. Spared, remyelinated, and demyelinated axons were judged according to criteria established in previous literature (Arnett et al., 2001; Mason et al., 2001). Briefly, spared axons were defined by their thick, multilayered myelin sheath, remyelinated axons were defined by the presence of a thin, dark myelin sheath covering the circumference of an axon, and demyelinated axons were defined by the absence of a myelin sheath covering the circumference of the axon. The proportion of each subtype was quantified for each animal and expressed as a percentage of the total number of axons analyzed.

\section{Adult oligodendrocyte precursor cell culture}

A razor blade was used to coronally cut the adult virgin female forebrain $2 \mathrm{~mm}$ caudal of tip of the forebrain (in which the olfactory bulbs join the brain) and again $3 \mathrm{~mm}$ caudal to that point. From the resulting $3 \mathrm{~mm}$ piece of forebrain, the corpus callosum was dissected cleanly from the surrounding cortex and striatum, with care to exclude the subventricular zone. The tissue, pooled from three animals, was transferred into media hormone mix (MHM) containing $1.33 \mathrm{mg} / \mathrm{ml}$ trypsin, $0.67 \mathrm{mg} / \mathrm{ml}$ hyaluronidase, and $0.2 \mathrm{mg} / \mathrm{ml}$ kynurenic acid (all from Sigma), and then incubated for $20 \mathrm{~min}$ at $37^{\circ} \mathrm{C}$. After complete trituration with a micropipette, the suspension was transferred into the same volume of media containing $0.7 \mathrm{mg} / \mathrm{ml}$ trypsin inhibitor (Roche). This suspension was spun down at $600 \mathrm{rpm}$ for $5 \mathrm{~min}$, resuspended, and then plated at a density of $1000-2000$ cells $/ \mathrm{ml}$ in a six-well plate in defined media (MHM) composed of DMEM/F-12 (1:1), glucose (0.6\%), glutamine (2 $\mathrm{mm})$, sodium bicarbonate $(3 \mathrm{~mm})$, HEPES $(5 \mathrm{~mm})$, insulin $(25 \mu \mathrm{g} / \mathrm{ml})$, transferrin $(100 \mu \mathrm{g} / \mathrm{ml})$, progesterone $(20 \mathrm{nM})$, putrescine $(60 \mu \mathrm{M})$, selenium chloride $(30 \mathrm{~nm})$ [all from Sigma, except that glutamine was from Invitrogen], and $100 \mathrm{ng} / \mathrm{ml}$ PDGF-AA (human recombinant; PeproTech, Rocky Hill, NJ) with or without mouse recombinant prolactin. After $10-12 \mathrm{~d}$ in vitro, the total number of primary neurospheres was counted, and the number of neurospheres greater or $<50 \mu \mathrm{m}$ in diameter was quantified. To phenotype the neurospheres, whole neurospheres were plated onto poly-L-ornithine-coated coverslips at a density of 10-20 neurospheres per milliliter per well in 24-well plates in the presence of $10 \%$ fetal bovine serum. After $3 \mathrm{~d}$ in vitro, coverslips were fixed in $4 \%$ paraformaldehyde in PBS and incubated with mouse anti- $\beta$-tubulin III antibody (1:1000; Sigma), mouse anti-O4 (1:10; Chemicon, Temecula, CA), and rabbit anti-GFAP (1:100; Sigma) in $0.3 \%$ Triton X-100/PBS containing $10 \%$ NGS. After washing in PBS, the appropriate rhodamine-, FITC-, and 7-amino-4methylcoumarin-3-acetic acid- conjugated secondary antibodies (1:200; Jackson ImmunoResearch) were applied. Labeled cells were counterstained with Hoechst 33258 and mounted on glass slides with Fluorsave (Calbiochem, San Diego, CA). The percentage of neurospheres containing neurons, astrocytes, and/or oligodendrocytes was determined for each condition.

\section{Statistical analysis}

Values are mean \pm SEM. Statistical analyses were performed using GraphPad (San Diego, CA) Prism software version 4.0b. Comparisons 
A
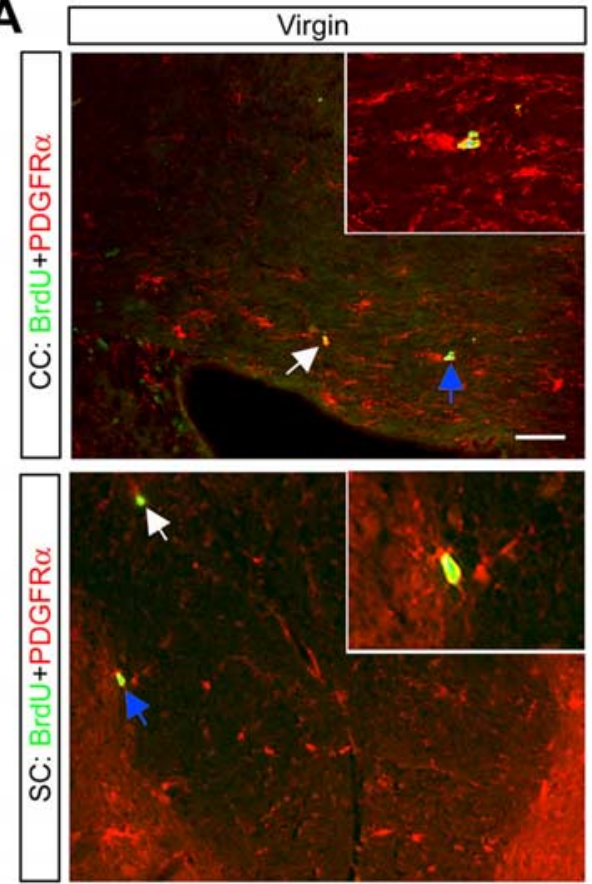

B

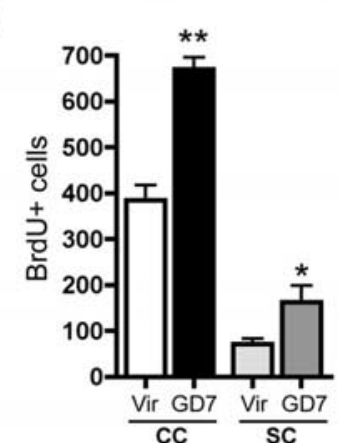

C

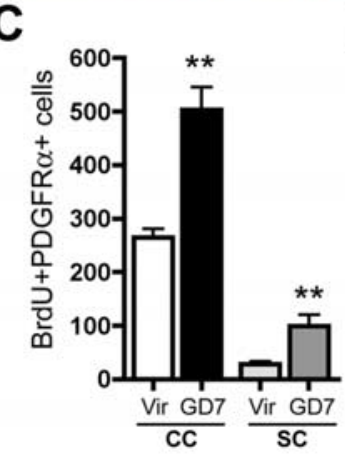

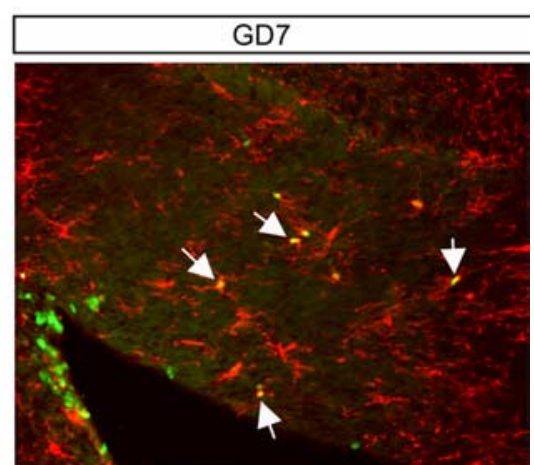

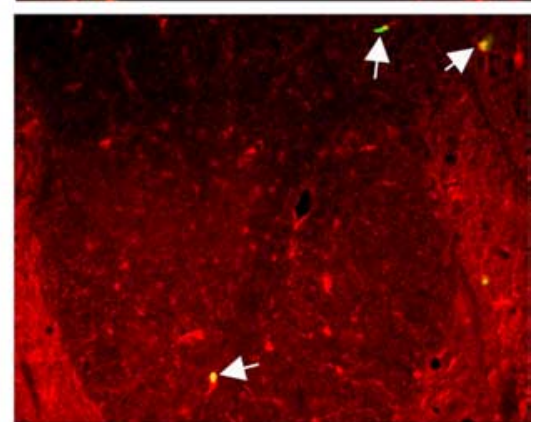

D

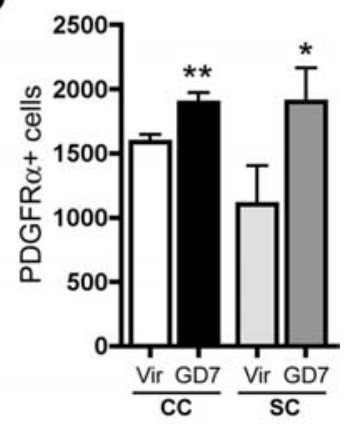

E

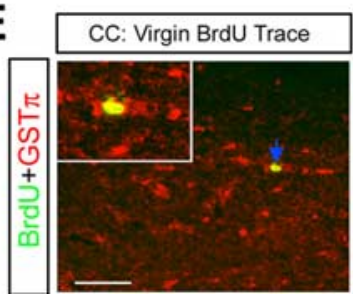

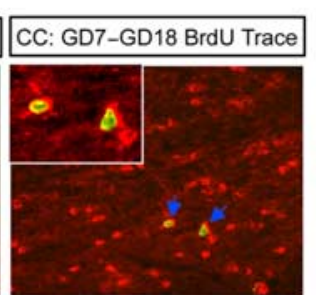

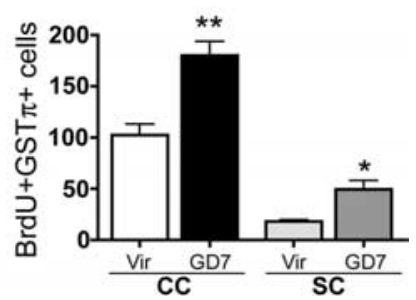

Figure 1. Pregnancy promotes increased OPC proliferation and the generation of new oligodendrocytes in the maternal CC and SC. $\boldsymbol{A}-\boldsymbol{D}$, Fluorescence micrographs $(\boldsymbol{A})$ and quantification demonstrate increases in the number of BrdU ${ }^{+}$cells $(\boldsymbol{B})$ $\mathrm{BrdU}^{+}$PDGFR $\alpha^{+}$cells $(\boldsymbol{C}$; unpaired $t$ test; CC, $n=3 ; \mathrm{SC}, n=5)$, and PDGFR $\alpha^{+}$cells (D; unpaired $t$ test; CC, $\left.n=7 ; \mathrm{SC}, n=5\right)$ in the CC and SC of GD7 pregnant females relative to virgins (arrows indicate BrdU ${ }^{+}$PDGFR $\alpha{ }^{+}$cells; colabeled cells shown in insets are indicated with blue arrows). The image in the CC is taken in the body of the CC above the right ventricle, and the image of the SC is specifically of the dorsal funiculus. $\boldsymbol{E}$, Fluorescence micrographs and quantification demonstrate increases in the number of newly generated oligodendrocytes (BrdU ${ }^{+} \mathrm{GST} \pi^{+}$cells) in the CC (arrows indicate BrdU ${ }^{+}$GST $\pi^{+}$cell examples; colabeled cells shown in inset are indicated with blue arrows) and SC of GD7-GD18 BrdU trace animals relative to virgin trace animals $11 \mathrm{~d}$ after BrdU treatment (unpaired $t$ test; $\mathrm{CC}, n=3 ; \mathrm{SC}, n=5$ ). Values are means $\pm \mathrm{SEM}$; ${ }^{*} p<0.05,{ }^{* *} p<0.01$. Scale bars, $50 \mu \mathrm{m}$.

\section{Results}

Increased OPC proliferation and oligodendrocyte generation in the maternal CNS

We first tested the hypothesis that pregnancy leads to an increase in OPC proliferation and generation in the maternal CNS. Virgin or timed pregnant GD7 females were injected with BrdU six times over $10 \mathrm{~h}$ and killed $0.5 \mathrm{~h}$ after the final injection to label dividing/newly generated OPCs in the CC and SC. Quantification of the total number of immunoreactive cells in 12 sections of the CC or SC of each animal was performed as described in Materials and Methods. At GD7, the number of $\mathrm{BrdU}^{+}$cells was doubled in these regions compared with virgin controls (CC, $p<0.01$; SC, $p<0.05$; unpaired $t$ test; $n=3$ ) (Fig. $1 A, B$ ). Double immunolabeling for BrdU and the OPC marker PDGFR $\alpha$ at GD7 revealed a 91 and 260\% increase, relative to virgins, in the number of dividing/newly generated OPCs in the CC $(p<0.01 ; n=3)$ and SC $(p<0.01$; $n=5$ ), respectively (unpaired $t$ test) (Fig. $1 A, C)$. Furthermore, the total number of PDGFR $\alpha^{+}$OPCs was increased by $20 \%$ in the CC ( $p<0.01$; unpaired $t$ test; $n=7)$ and $80 \%$ in the SC $(p<0.05$; unpaired $t$ test; $n=$ 5 ) in GD7 females relative to virgins (Fig. $1 A, D)$. The pregnancy-induced increases in OPC number were not attributable to increased cell survival because no difference in the number of cells expressing activated caspase- 3 was observed in the CC of virgin versus GD7 animals (data not shown).

To determine whether increased OPC proliferation/generation ultimately resulted in the generation of new oligodendrocytes in the maternal CNS, virgin and GD7 pregnant females received BrdU and were killed $11 \mathrm{~d}$ later to trace the fate of the newly generated cells (pregnant BrdU trace animals are referred to as GD7GD18). Double immunolabeling with BrdU and the mature oligodendrocyte marker GST $\pi$ (Arnett et al., 2001) revealed a $74 \%$ (CC, $p<0.01$; unpaired $t$ test; $n=3$ ) and $173 \%$ (SC, $p<0.01$; unpaired $t$ test; $n=5$ ) increase in the number of new oligodendrocytes in the CC and $\mathrm{SC}$, respectively, in GD7-GD18 relative to virgin traced females (Fig. $1 E$ ). Similar increases in OPC proliferation/generation and oligodendrocyte generation were also

between two groups were made using an unpaired $t$ test. Analyses of paired observations between two experimental conditions (adult OPC neurosphere culture experiments) were made using a paired $t$ test. Statistical analysis of experiments involving multiple groups was performed using a one-way ANOVA, followed by a Tukey's honest significant difference (HSD) post hoc analysis to compare all groups with each other or a Dunnett's post hoc analysis to compare changes specifically with virgin controls ( post hoc test used is noted in the text). observed in the maternal optic nerve (supplemental Table 1, available at www.jneurosci.org as supplemental material).

\section{Myelination increases in the maternal CNS during the postpartum period}

We investigated the potential of the newly generated oligodendrocytes for myelination by first characterizing the formation of 
processes by these cells (Buttery and ffrench-Constant, 2001). Mature GST $\pi^{+}$oligodendrocytes in the CC of 60-d-old virgin females were randomly imaged with confocal $z$-stacks, revealing an average of three to four, highly branched, GST $\pi^{+}$processes extending from the cell soma ( $n=3 ; N \geq 25$ cells per animal) (Fig. 2A). Newly generated oligodendrocytes $\left(\mathrm{BrdU}^{+} \mathrm{GST} \pi^{+}\right.$ cells) in the CC of 60-d-old GD7-GD18 BrdU traced pregnant females extended significantly fewer GST $\pi^{+}$processes than mature oligodendrocytes in virgins, with an average of one to two per cell soma ( $p<0.001$; one-way ANOVA with Tukey's HSD post hoc test; $n=3 ; N \geq 25$ cells per animal) (Fig. $2 A$ ), suggesting they were still maturing at the end pregnancy. Longer tracing times of GD7-P7 and GD7-P14 revealed that the newly generated cells eventually developed the fully mature three to four GST $\pi^{+}$processes per soma $(n=3 ; N \geq 25$ cells per animal) (Fig. $2 A)$.

Pregnancy-generated oligodendrocytes appear to arborize in the postpartum period; therefore, we asked whether there might be associated changes in myelination. Confocal imaging of cells triple labeled with $\operatorname{BrdU}, \mathrm{GST} \pi$, and MBP, the major protein constituent of myelin, revealed that virtually all newly generated $\mathrm{BrdU}^{+} \mathrm{GST} \pi^{+}$oligodendrocytes in the CC of GD7-GD18 animals ( $\sim 98 \% ; n=3 ; N \geq 25$ cells per animal) and GD7-P7 animals ( $\sim 96 \% ; n=3 ; N \geq 25$ cells per animal) express MBP (Fig. 2B). Western blot analysis of MBP expression in the CC and $\mathrm{SC}$ over the course of pregnancy and the postpartum period revealed significant increases in the $18,17.2$, and $14 \mathrm{kDa}$ isoforms at P7 and P14 relative to 6-week-old virgins (one-way ANOVA with Dunnett's post hoc test; $n=4$ ) (Fig. $2 C, D$ ). This result was not simply attributable to differences in age because no increase in MBP expression was observed in the CC and SC of 6-week-old versus 12 -week-old adult virgin females (data not shown). Finally, we used EM to ask whether there was a change in the number of myelinated axons in the maternal CNS (Fig. 2E). Remarkably, we observed a $50 \%$ increase in the number of myelinated axons in the genu of the CC in P14 females relative to agematched 11-week-old virgins ( $p<0.01$; unpaired $t$ test; $n=4$ ) (Fig. 2E). This was not simply attributable to changes in axonal packing density, because no significant change was observed in the total number of axons (myelinated plus unmyelinated) per $100 \mu \mathrm{m}^{2}$ in the genu of virgin $(888 \pm 131)$ versus P14 females (789 $\pm 62 ; n=3 ; p>0.05$; unpaired $t$ test). Therefore, although it is not clear what proportion of newly generated oligodendrocytes are actively engaging in the myelination of axons, we find that pregnancy-induced oligodendrocyte generation is clearly associated with a postpartum increase in myelination within the maternal CNS.

\section{Myelin repair is enhanced in the maternal CNS}

Preexisting, mature oligodendrocytes are unable to contribute to remyelination in the CNS, and the process of myelin repair depends on increased OPC proliferation and the generation of new oligodendrocytes (Polito and Reynolds, 2005). To test whether pregnancy-induced OPC proliferation enhances the intrinsic capacity of the maternal CNS to repair demyelination, we used a spontaneously remyelinating model of acute demyelinating injury in which the detergent lysolecithin is injected directly into the dorsal funiculus of the spinal cord (Jeffery and Blakemore, 1995; Larsen et al., 2003). Remyelination in this model has begun by $7 \mathrm{~d}$ after lesion, is primarily completed after $23 \mathrm{~d}$ (Jeffery and Blakemore, 1995), and can be assessed by measurements of the lesion size (Larsen et al., 2003).

Virgin and GD3 pregnant females received dorsal funiculus lysolecithin lesions and were analyzed $7 \mathrm{~d}$ (GD3-GD10) and $11 \mathrm{~d}$ (GD3-GD14) later to assess the proportion of the dorsal funiculus that remained lesioned (Fig. $3 A, B$ ). In the pregnant GD3GD10 animals, the volume of the lesion (see Materials and Methods) was decreased in size by $37 \%$ relative to matched virgin controls ( $p<0.05$; unpaired $t$ test; $n=4$ ) (Fig. 3B). By GD14, the lesion volume in GD3-GD14 animals was 52\% smaller than that of matched virgin controls ( $p<0.01$; unpaired $t$ test; $n=8$ ) (Fig. $3 A, B)$. We asked whether pregnancy might decrease the lesion size by promoting oligodendrocyte generation and enhanced remyelination. Lesioned virgin and GD3 pregnant females received BrdU injections for $4 \mathrm{~d}$ after lesion and were analyzed at $14 \mathrm{~d}$ after lesion to trace the generation of new cells (Fig. 3C). We observed an $80 \%$ increase in the number of $\mathrm{BrdU}^{+} \mathrm{GST} \pi^{+}$oligodendrocytes in the lesioned dorsal funiculus of GD3-GD14 pregnant animals relative to virgins ( $p<0.05$; unpaired $t$ test; $n=7$ ) (Fig. $3 D, E)$. Finally, we used EM to count the relative numbers of axons that were demyelinated, remyelinated, or spared within the lesion center of virgin versus GD3-GD14 females (Fig. 3F, G). Relative to virgin controls, GD3-GD14 females had 75\% fewer demyelinated axons ( $p<0.01$; unpaired $t$ test; $n=4)$, a $35 \%$ increase in the proportion of remyelinated axons $(p<0.01$; unpaired $t$ test; $n=4$ ), but no significant change in the number of spared axons. Therefore, although the demyelinating lesions in pregnant females are already reduced in size by $7 \mathrm{~d}$ after lesion relative to virgin females, our BrdU tracing and EM results suggest that the decreased lesion size is primarily attributable to increased oligodendrocyte generation and enhanced remyelination rather than neuroprotection during pregnancy.

\section{PRL signaling regulates pregnancy-induced OPC proliferation}

Pregnancy-induced OPC proliferation occurred during the first week of pregnancy, coincident with gestational increases in PRL levels (Freeman et al., 2000). RT-PCR and Western blotting revealed expression of the long form of PRLR in the adult virgin female CC and SC (Fig. 4A,B). A subpopulation of PDGFR $\alpha^{+}$ OPCs coexpressed the PRLR in both the CC $(\sim 42 \% ; n=2)$ and SC $(\sim 47 \% ; n=2)$ (Fig. $4 C)$, suggesting that these cells may respond to increases in PRL levels. We therefore asked whether PRLR signaling is required for the pregnancy-induced increases in OPC proliferation. Because $\mathrm{Prlr}^{-1-}$ mice cannot become pregnant (Freeman et al., 2000), we compared virgin and GD7 Prlr ${ }^{+/+}$ and $\mathrm{Prlr}^{+/-}$females. The number of dividing OPCs $\left(\mathrm{BrdU}^{+} \mathrm{PDGFR} \alpha^{+}\right.$cells) in the CC of GD7 pregnant $\mathrm{Prlr}^{+/+}$ females was increased by $90 \%$ relative to virgins $(p<0.01 ; n=$ 4), but, in the CC of GD7 Prlr ${ }^{+/-}$females, OPC proliferation was not significantly different from virgin controls $(p>0.05$; oneway ANOVA with Tukey's HSD post hoc test; $n=4$ ) (Fig. $4 D$ ).

These findings suggest that PRL can promote OPC proliferation and the generation of new oligodendrocytes in the adult female CNS. To test this, we infused virgin female mice with VEH or PRL subcutaneously for $3 \mathrm{~d}$ and injected BrdU on the final day. Relative to VEH, PRL infusions induced a $114 \%(p<0.01$; unpaired-test; $n=5)$ and $57 \%(p<0.05$; unpaired $t$ test; $n=5)$ increase in the number of dividing OPCs $\left(\mathrm{BrdU}^{+} \mathrm{PDGFR} \alpha^{+}\right.$ cells) in the CC and SC, respectively (Fig. $4 E$ ). BrdU tracing revealed that PRL infusions also increased the generation of new oligodendrocytes ( $\mathrm{BrdU}^{+} \mathrm{GST} \pi^{+}$cells) in both the CC and SC by $55 \%(p<0.01$; unpaired $t$ test; $n=5)$ and $124 \%(p<0.01$; unpaired $t$ test; $n=5$ ), respectively (Fig. $4 F$ ). As in pregnancy, the increases were attributable to enhanced OPC proliferation, not cell survival, because we observed no change in the number of 

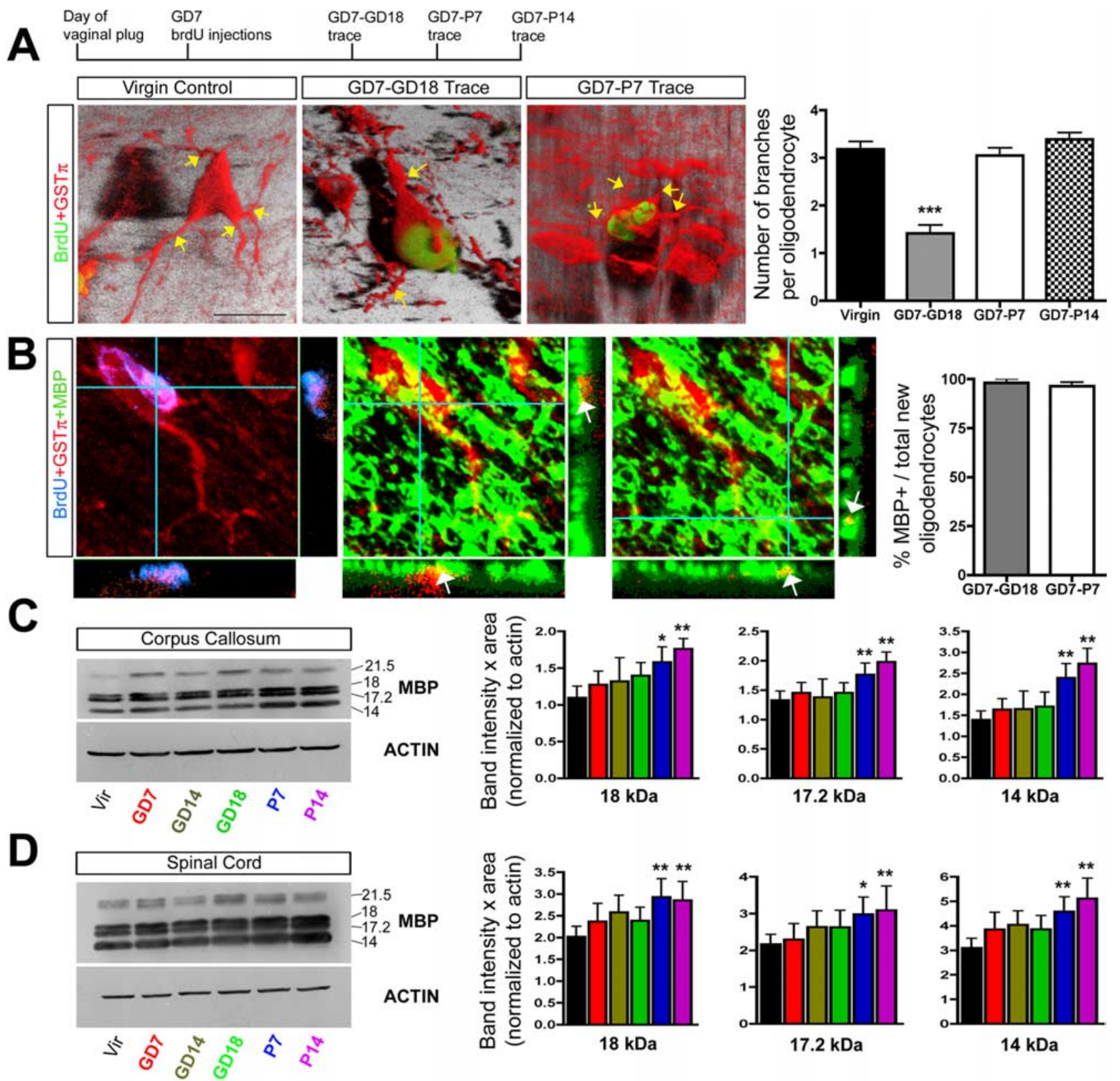

$17.2 \mathrm{kDa}$

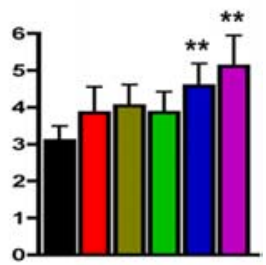

$14 \mathrm{kDa}$
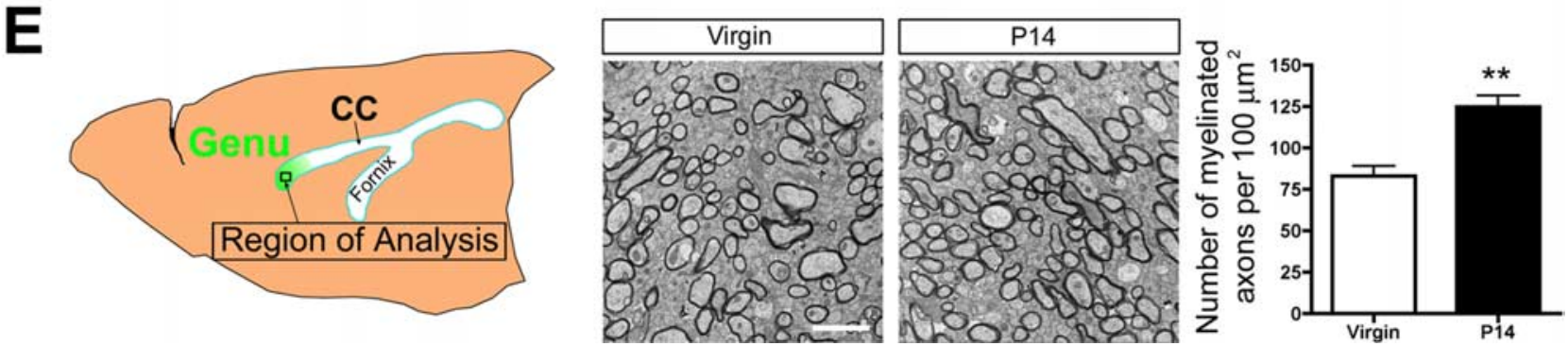

Figure 2. Newly generated oligodendrocyte maturation occurs during the postpartum period and is associated with increases in MBP levels and myelinated axons. A, Confocal $z$-stack images (3-D rendered images shown) and quantification of GST $\pi^{+}$processes (indicated by yellow arrows) extending from the soma of mature (GST $\pi^{+} ; 60$-d-old virgin animals) and newly generated oligodendrocytes (BrdU ${ }^{+} \mathrm{GST} \pi^{+}$) located in the CC of GD7-GD18, GD7-P7, and GD7-P14 BrdU trace pregnant animals (one-way ANOVA with Tukey's HSD post hoc test; $n=3, N \geq 25$ cells per animal). Quantification suggests that new oligodendrocytes born on GD7 ultimately attain a normal complement of three to four processes by P7. $B$, Quantification using confocal imaging was used to determine the percentage of newly generated oligodendrocytes (BrdU ${ }^{+}$GST $\pi^{+}$cells) in the CC of GD7-GD18 and GD7-P7 BrdU trace animals (BrdU ${ }^{+}$GST $\pi^{+}$cell) that express MBP ( $n=3$, $N \geq 25$ cells per animal). The majority of new oligodendrocytes in the maternal CNS were observed to express MBP (arrows indicate yellow regions of coexpression in the $z$-axis under confocal microscopy; immunoreactivity was primarily observed within the processes rather than the cell soma). C, $\boldsymbol{D}$, Western blot analysis of MBP expression in the CC (C) and SC (D) over the course of pregnancy and the postpartum period demonstrated significantly increased levels of the 18,17.2, and 14 kDa MBP isoforms at P7 and P14 relative to virgin controls (one-way ANOVA with Dunnett's post hoc test; $n=4$ or more animals per group). E, Quantification of the number of myelinated axons in the genu of the CC in age-matched 11-week-old virgins ( $n=4)$ and P14 mothers using EM (unpaired $t$ test; $n=4$ ) revealed a significant increase in the number of myelinated axons in the postpartum females. Values are means \pm SEM; ${ }^{*} p<0.05,{ }^{* *} p<0.01,{ }^{* * *} p<0.001$. Scale bars: $A, 10 \mu \mathrm{m} ; E, 2 \mu \mathrm{m}$. 
activated caspase- $3^{+}$cells within the CC of PRL- versus VEH-infused animals (data not shown).

The expression of the PRLR by a subpopulation of adult OPCs suggests that PRL acts directly on these cells to increase their proliferation. To test whether PRL can act on OPCs in the white matter of the adult CNS to increase their proliferation and generation of oligodendrocytes, we isolated PDGF-responsive OPCs in vitro as neurospheres (Chojnacki and Weiss, 2004). The CC of adult virgin females was dissociated and cultured in the presence of PDGF for 10-12 d in vitro, resulting in the formation of adult OPC neurospheres (Fig. 5A). After differentiation in 1\% FBS for $3 \mathrm{~d}$, the majority of adult OPC neurospheres contained astrocytes $\left(\mathrm{GFAP}^{+}\right)$ and oligodendrocytes $\left(\mathrm{O}^{+}\right)(\sim 80 \%)$, and a minority contained astrocytes only $(\sim 15 \% ; n=4)$ (Fig. 5A-C) (supplemental Table 2, available at www.jneurosci.org as supplemental material). PRL addition to the cultures increased the number of adult OPC neurospheres by $38 \%$ relative to PDGF alone ( $p<0.01$; paired $t$ test; $n=$ $4)$. Furthermore, the proportion of neurospheres that were $>50 \mu \mathrm{m}$ in diameter was increased by $63 \%$ in the PRL condition ( $p<0.01$; paired $t$ test; $n=4$ ) (Fig. $5 D)$. PRL did not change the primarily bipotent astrocyte-oligodendrocyte phenotype of the adult OPC (supplemental Table 2, available at www.jneurosci.org as supplemental material). However, the number of $\mathrm{O}_{4}{ }^{+}$oligodendrocytes generated per neurosphere was doubled in the PRL plus PDGF growth condition relative to PDGF alone (PRL plus PDGF, $13 \pm 2$, $n=3, N=20$ individual neurospheres were quantified in total; PDGF, $6 \pm 3, n=3, N=11 ; p<0.05$; unpaired $t$ test) (Fig. $5 E$ ).

In summary, although we have not ruled out potential paracrine mechanisms for the actions of PRL, our functional data and expression data strongly suggest that PRL signaling likely acts on a subpopulation of OPCs in the maternal CNS to mediate the pregnancy-induced increase in OPC proliferation and oligodendrocyte generation.

\section{PRL treatment promotes myelin repair in virgin females}

We hypothesized that PRL administration might enhance white matter regeneration in a manner similar to pregnancy. Daily intraperitoneal injections of $20 \mu \mathrm{g}$ of PRL for 7 consecutive days increased the number of $\mathrm{BrdU}^{+} \mathrm{PDGFR} \alpha^{+}$cells by $169 \%$ in the uninjured virgin female spinal cord relative to $\mathrm{VEH}(p<0.01$; unpaired $t$ test; $n=3$ ). Subsequently, virgin female mice received lysolecithin lesions in the SC dorsal funiculus followed immediately by intraperitoneal injections of PRL or VEH for 7 consecutive days, BrdU injections on postlesion days 4, 5, 6, and 7, and were killed at $14 \mathrm{~d}$ after lesion. We observed a $74 \%$ increase in the number of BrdU ${ }^{+} \mathrm{GST} \pi^{+}$oligodendrocytes in the lesioned dorsal funiculus of PRL-treated animals relative to VEH controls $(\mathrm{VEH}, 480 \pm 120, n=8$; PRL, $836 \pm 104, n=9 ; p<0.05$; unpaired $t$ test) (Fig. 6A). Furthermore, the proportion of the dorsal funiculus that remained demyelinated after $14 \mathrm{~d}$ was reduced by $46 \%$ in PRL-treated animals relative to VEH controls (lesion size index: VEH, $9 \pm 2, n=6$; PRL, $5 \pm 1, n=6$; $p<0.05$; unpaired $t$ test) (Fig. $6 B$ ). Therefore, PRL treatments mimicked the regenerative effects of pregnancy on white matter damage in virgin females.

\section{Discussion}

The present study suggests that white matter changes occur in the maternal CNS. These changes are initiated during early pregnancy and include increases in OPC proliferation, oligodendrocyte generation, MBP expression, and, ultimately, an increase in the number of myelinated axons. Remarkably, we find that this process is associated with an enhanced capacity to regenerate myelin damage. PRL signaling is necessary and sufficient for the pregnancy-induced increase in OPC proliferation, and PRL treatments mimic the regenerative effects of pregnancy on myelin damage in virgin females. These results identify a novel form of white matter plasticity in the adult CNS and suggest that PRL may have therapeutic potential for the treatment of white matter damage. 
A

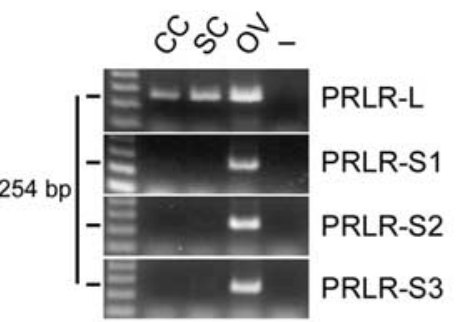

C

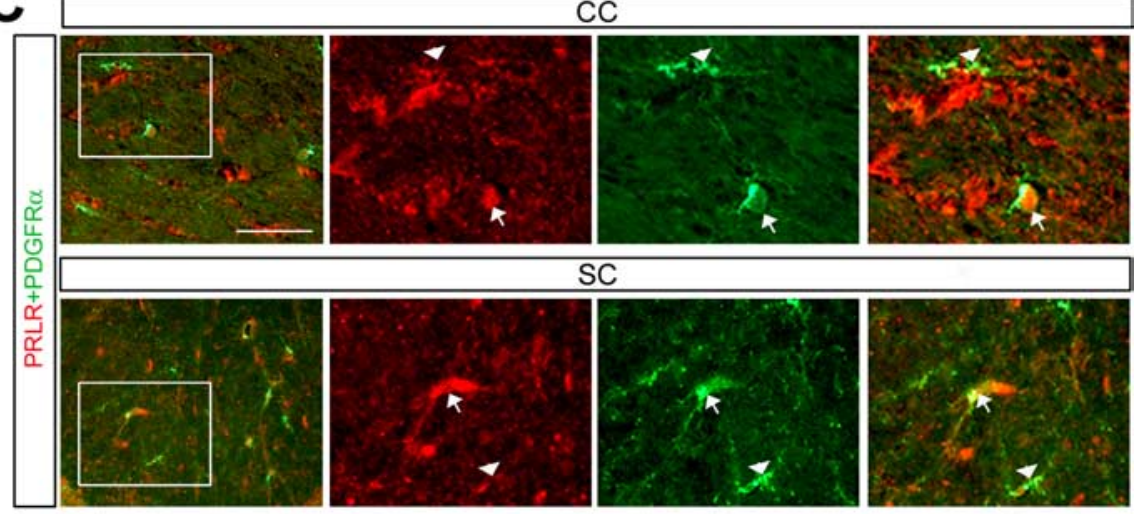

B

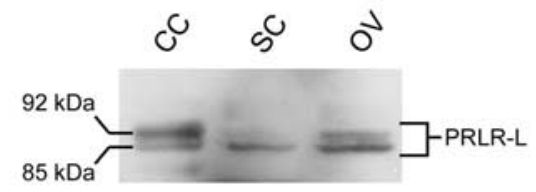

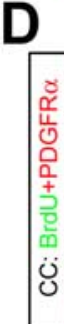

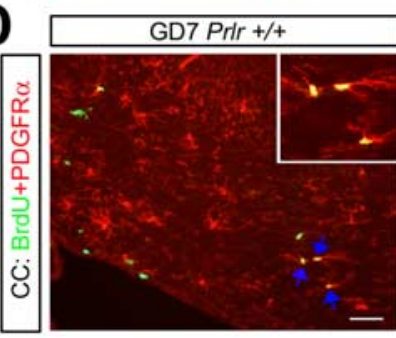

E

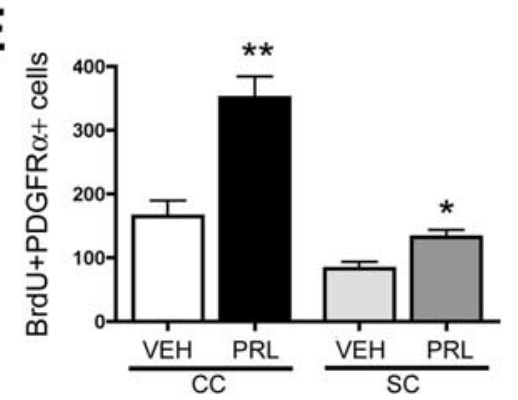

1999), stress (Mirescu and Gould, 2006), novel odors (Rochefort et al., 2002), and pregnancy (Shingo et al., 2003). Therefore, neurogenesis has been established as a major form of experience-dependent plasticity in the adult CNS. In contrast, virtually nothing is known about the capacity of the adult brain for adaptive white matter changes, despite the fact that adult OPCs exist throughout the brain and are capable of dividing to give rise to new oligodendrocytes (Gensert and Goldman, 1996; Levison et al., 1999; Tang et al., 2000; Wu et al., 2001; Dawson et al., 2003; Menn et al., 2006). Recent work has found that at least some newly generated oligodendrocytes in the uninjured adult brain clearly contribute to the myelination of axons (Menn et al., 2006). Furthermore, in addition to adult OPCs, neural stem cells (NSCs) within the adult subventricular zone also generate new oligodendrocytes (Nait-Oumesmar et al., 1999; PicardRiera et al., 2002; Hack et al., 2005; Menn et al., 2006). Our results suggest that PRL signaling can act on a subpopulation of OPCs during pregnancy to promote their proliferation, but, given that NSC proliferation also increases during pregnancy (Shingo et al., 2003), both OPCs and NSCs may contribute to the increased generation of new oligodendrocytes in the maternal CNS.

Plasticity at the level of myelination has been well documented during brain development (Dong and Greenough, 2004), and, in part, myelination in the developing brain is an activity-dependent phenomenon (Szeligo and Leblond, 1977; Tauber et al., 1980; Sirevaag and Greenough, 1987; Demerens et al., 1996; Stevens et al., 2002). In the adult CNS, the total number of oligodendrocytes (Dawson et al., 2003; Peters and Sethares, 2004) and myelinated axons (Sturrock, 1980; Nunez et al., 2000) increases with age, suggesting that myelination continues throughout life. Surprisingly, however, only very recently has the potential for white matter plasticity in the adult brain been demonstrated (Bengtsson et al., 2005). The fact that the female brain in both humans (Gur et al., 1999; Allen et al., 2003; Haier et al., 2005) and rodents (Mack et al., 1995; Kim and Juraska, 1997) tends to have a disproportionately smaller amount of white matter than the male brain suggests that mechanisms underlying adult white matter plasticity might ex-

\section{White matter plasticity in the maternal CNS}

Adult olfactory or hippocampal neurogenesis can be dynamically regulated by such things as environmental enrichment (Kempermann et al., 1997; Nilsson et al., 1999), exercise (van Praag et al., hibit gender differences. In support of this, a recent study has shown that oligodendrocyte turnover is significantly higher in adult females than males (Cerghet et al., 2006). Although our study has revealed that pregnancy, a situation specific to females, 
A
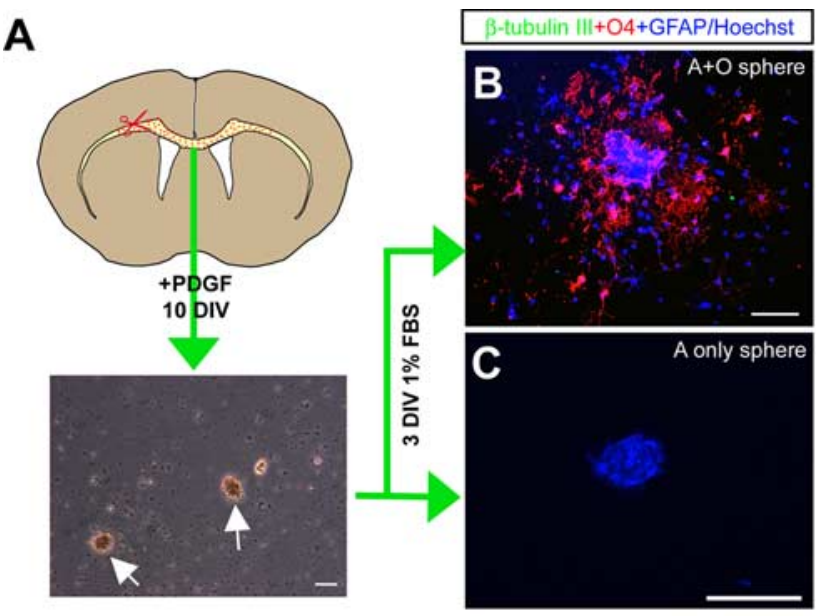

D
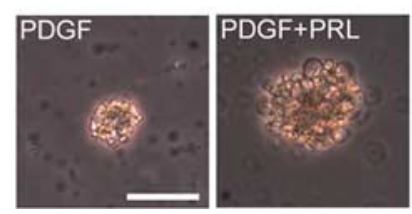

E
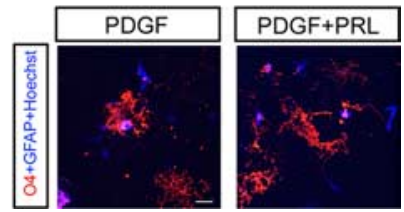

Figure 5. PRL can act directly in vitro to increase $\mathrm{OPC}$ proliferation and the generation of new oligodendrocytes. $\boldsymbol{A}-\boldsymbol{C}$, Dissociated cells derived from the C $\mathrm{C}$ adult female virgins gave rise to neurospheres after 10-12 d in vitro (DIV) in the presence of PDGF. Cells within adult OPC neurospheres differentiated in the presence of $1 \% \mathrm{FBS}$ to form oligodendrocytes $\left(04^{+}\right)$and astrocytes $\left(\mathrm{GFAP}^{+}\right)$but not neurons $\left(\beta\right.$-tubulin-III $\left.{ }^{+}\right)$. Approximately $80 \%$ of adult $\mathrm{OPC}$ neurospheres gave rise to oligodendrocytes and astrocytes $(A+0)$, whereas a minority gave rise to astrocytes only (A only; $\sim 15 \% ; n=4$ ) (supplementary Table 2, available at www.jneurosci.org as supplemental material). $\boldsymbol{D}$, Representative images of OPC neurospheres generated in the presence of either PDGF or PRL plus PDGF. The addition of PRL to adult OPC neurosphere cultures significantly increased the number of neurospheres formed by $38 \%$ relative to PDGF alone $(p<0.01$; paired $t$ test; $n=4)$, as well as the proportion of neurospheres that were $>50 \mu \mathrm{m}$ in diameter by $63 \%$ in the PRL condition ( $p<0.01$; paired $t$ test; $n=4$ ). $\boldsymbol{E}$, Adult OPCs grown in the presence of PRL plus PDGF and differentiated for $3 \mathrm{~d}$ in vitro in the presence of $1 \% \mathrm{FBS}$ had a significantly greater number of $04^{+}$oligodendrocytes per neurosphere than those grown in PDGF alone (PRL plus PDGF, $13 \pm 2, n=3, N=20$ individual neurospheres were quantified in total; PDGF, $6 \pm 3, n=3, N=11 ; p<0.05$; unpaired $t$ test). Scale bars: $\boldsymbol{A}, \boldsymbol{D}, \boldsymbol{E}, 50 \mu \mathrm{m} ; \boldsymbol{B}, \boldsymbol{C}$, $100 \mu \mathrm{m}$.

promotes increased adult female OPC proliferation, oligodendrocyte generation, and myelination, we found that PRL infusions also increased OPC proliferation and the generation of new oligodendrocytes in males (data not shown). It is possible that specific experiences leading to altered PRL signaling in males, such as paternity (Schradin and Anzenberger, 1999), might promote male-specific white matter changes.

Our study has demonstrated that, in the absence of an injury, newly generated oligodendrocytes born during early pregnancy mature in the maternal CNS, during the postpartum period, by virtue of arborization and the acquisition of MBP expression. This process is associated with increases in total MBP expression levels and an increase in the total number of myelinated axons in the CC. Maternal white matter changes represent a form of plasticity that may be a physiological adaptation to pregnancy. Effective maternal behavior is a challenge, requiring cognitive changes that enhance foraging abilities (Kinsley et al., 1999; Lambert et al., 2005), learning and memory (Kinsley et al., 1999; Love et al., 2005), and social learning (Fleming and Walsh, 1994) and alter sensory and emotional responses (Neumann, 2001; Walker et al., 2004). Maternal white matter changes may be initiated to meet these demands, perhaps by increasing the fidelity of neurotransmission within specific axon tracts and promoting the repair of any existing white matter damage to enhance CNS function. For consideration in future work, it is interesting that the majority of axons within the adult rodent CC are unmyelinated (Sturrock, 1980; Mack et al., 1995), suggesting that new oligodendrocytes might select subpopulations of naked maternal CC axons to myelinate. Future studies might investigate the possibility that pregnancy promotes changes within specific axon tracts, making subpopulations of callosal axons particularly receptive to myelination by new oligodendrocytes.

\section{Possible relationship of pregnancy, PRL-induced} remyelination, and the remission of $\mathrm{MS}$

Patients suffering from MS experience a significant clinical improvement in their symptoms during late stages of pregnancy (van Walderveen et al., 1994; Confavreux et al., 1998; Voskuhl, 2003). Furthermore, animal models of MS, such as experimental allergic encephalomyelitis (EAE), also show significant symptomatic improvements during pregnancy (Voskuhl, 2003). The mechanisms mediating the pregnancy-induced remission of MS are not fully understood, but it is tempting to speculate that the enhanced capacity for remyelination we described in the maternal CNS might be a contributing factor. PRL may even have therapeutic potential for the treatment of MS white matter damage, although its potential proinflammatory effects could be detrimental to nonpregnant MS patients (Draca and Levic, 1996; Chikanza, 1999). Interestingly, the proinflammatory cytokine tumor necrosis factor $\alpha$ also promotes OPC proliferation and CNS remyelination (Arnett et al., 2001). In pregnancy, PRL levels are elevated during the pregnancy-induced shift from proinflammatory Th1 (T-helper 1 cells) to anti-inflammatory Th2-mediated immunity (Weetman, 1999), providing a window that may permit PRL-mediated myelin repair in MS. This immune shift is likely important to remission (Voskuhl, 2003) given that the disease relapses in the postpartum period when PRL levels are elevated, but maternal immunity returns to a Th1 bias.

To date, pregnancy-induced changes to immune system function, which have been suggested to be the primary mediators of pregnancy-induced MS remission, are primarily thought to occur through the actions of steroids. In particular, estrogens (estrone, estradiol, or estriol) are thought to play a major role in the shift from Th1- to Th2-mediated immunity during pregnancy, although numerous other molecules have been implicated (Voskuhl, 2003). Estrogen levels are significantly elevated during pregnancy, and estradiol treatments have been shown to inhibit EAE by depressing Th1 immune activity (Kim et al., 1999; Bebo et al., 2001; Ito et al., 2001). Recently, a phase II pilot trial was performed in which 10 women with MS were treated with oral estriol at levels similar to pregnancy (Sicotte et al., 2002). The results of this small clinical trial suggested that estriol treatments were beneficial in some of patients with relapsing-remitting MS and was associated with a reduced Th1 response and a significant reduction in gadolinium-enhancing lesion numbers and size. Although the beneficial effect of estrogen is thought to be reduced Th1 activity, improvements in the symptoms of MS may be attributable, in part, to the remyelination of lesions (Scolding and Franklin, 1997). Estrogen is one of the most potent activators of PRL secretion from the pituitary (Freeman et al., 2000). Therefore, the beneficial effects of estrogen therapies could partially be 
A
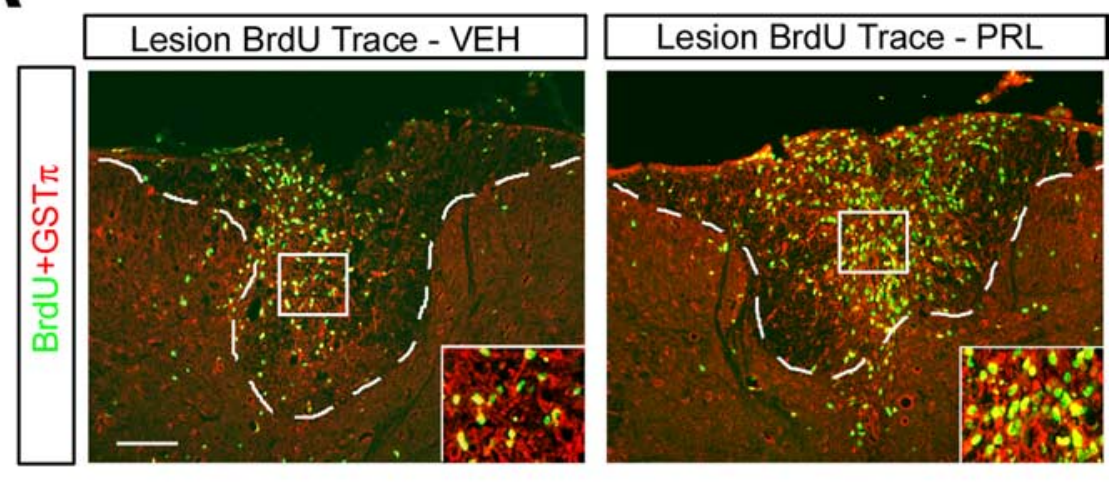

B

Rostral
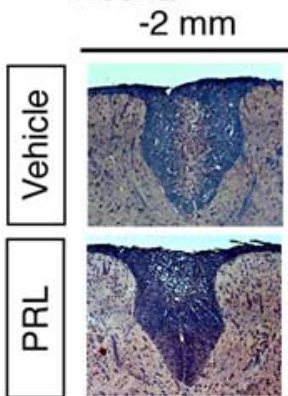

$-1 \mathrm{~mm}$
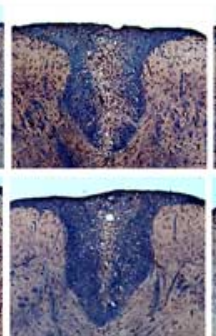

\begin{abstract}
Center
\end{abstract}

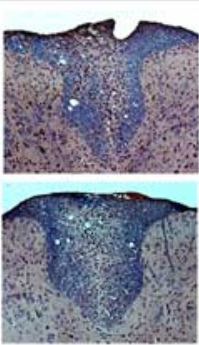

$+1 \mathrm{~mm}$

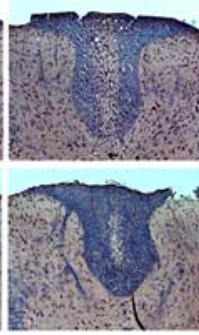

Figure 6. PRL treatments mimic the regenerative effects of pregnancy on myelin damage in virgin females. $\boldsymbol{A}$, Fluorescence micrographs of newly generated oligodendrocytes (BrdU ${ }^{+} \mathrm{GST} \pi{ }^{+}$cells) in the lysolecithin lesioned dorsal funiculus of VEHversus PRL-treated females after BrdU tracing revealed an increase in the number of newly generated oligodendrocytes in the lesion of PRL-treated females (VEH, $480 \pm 120, n=8$; PRL, $836 \pm 104, n=9 ; p<0.05$; unpaired $t$ test). $\boldsymbol{B}$, Luxol fast blue staining of myelin in the dorsal funiculus of PRL- and VEH-treated females and quantification of lesion size $14 \mathrm{~d}$ after lysolecithin lesions revealed a significant reduction in the size of the lesion of PRL-treated females relative to VEH (lesion size index: VEH, $9 \pm$ $2, n=6 ; \mathrm{PRL}, 5 \pm 1, n=6 ; p<0.05$; unpaired $t$ test). Values are means $\pm \mathrm{SEM}$. Scale bar, $100 \mu \mathrm{m}$.

related to elevated PRL levels. Future studies might be directed toward investigating therapeutic applications of PRL for promoting repair in MS in combination with immunomodulatory agents that negate proinflammatory responses.

\section{Potential for PRL treatment of white matter damage in non- autoimmune based neurological disorders}

White matter damage in the CNS has primarily been considered in the context of MS, but recent studies have demonstrated that demyelination is a major contributing factor to deficits arising in many neurological disorders, including spinal cord injury (Totoiu and Keirstead, 2005), stroke (Mori, 2002), and age-related dementia (Ferro and Madureira, 2002). Remarkably, pregnancy has been shown to attenuate the age-related decline in learning and memory (Gatewood et al., 2005), and it is again tempting to speculate that pregnancy-induced, PRL-mediated myelin repair is involved. Furthermore, results of recent studies have clearly demonstrated that enhancing remyelination after spinal cord injury through the transplantation of OPCs significantly improves recovery (Bambakidis and Miller, 2004; Cao et al., 2005; Lee et al., 2005; Karimi-Abdolrezaee et al., 2006). Moreover, efforts are underway to derive OPCs from human embryonic stem cell lines for the clinical treatment of spinal cord injury (Faulkner and
Caudal $+2 \mathrm{~mm}$

Keirstead, 2005; Keirstead et al., 2005). Together, these studies suggest that a molecule such as PRL, which can be systemically delivered to mobilize endogenous OPCs and promote intrinsic myelin repair, may have potential for the treatment of several neurological disorders associated with white matter pathology.

\section{References}

Allen JS, Damasio H, Grabowski TJ, Bruss J, Zhang W (2003) Sexual dimorphism and asymmetries in the gray-white composition of the human cerebrum. NeuroImage 18:880-894.

Arnett HA, Mason J, Marino M, Suzuki K, Matsushima GK, Ting JP (2001) TNF alpha promotes proliferation of oligodendrocyte progenitors and remyelination. Nat Neurosci 4:1116-1122.

Bambakidis NC, Miller RH (2004) Transplantation of oligodendrocyte precursors and sonic hedgehog results in improved function and white matter sparing in the spinal cords of adult rats after contusion. Spine J 4:16-26.

Bebo Jr BF, Fyfe-Johnson A, Adlard K, Beam AG, Vandenbark AA, Offner H (2001) Low-dose estrogen therapy ameliorates experimental autoimmune encephalomyelitis in two different inbred mouse strains. J Immunol 166:2080-2089.

Bengtsson SL, Nagy Z, Skare S, Forsman L, Forssberg H, Ullen F (2005) Extensive piano practicing has regionally specific effects on white matter development. Nat Neurosci 8:1148-1150.

Buttery PC, ffrench-Constant C (2001) Process extension and myelin sheet formation in maturing oligodendrocytes. Prog Brain Res 132:115-130.

Camarillo IG, Thordarson G, Moffat JG, Van Horn KM, Binart N, Kelly PA, Talamantes F (2001) Prolactin receptor expression in the epithelia and stroma of the rat mammary gland. J Endocrinol 171:85-95.

Cao Q, Xu XM, Devries WH, Enzmann GU, Ping P, Tsoulfas P, Wood PM, Bunge MB, Whittemore SR (2005) Functional recovery in traumatic spinal cord injury after transplantation of multineurotrophin-expressing glial-restricted precursor cells. J Neurosci 25:6947-6957.

Cerghet M, Skoff RP, Bessert D, Zhang Z, Mullins C, Ghandour MS (2006) Proliferation and death of oligodendrocytes and myelin proteins are differentially regulated in male and female rodents. J Neurosci 26:1439-1447.

Chikanza IC (1999) Prolactin and neuroimmunomodulation: in vitro and in vivo observations. Ann NY Acad Sci 876:119-130.

Chojnacki A, Weiss S (2004) Isolation of a novel platelet-derived growth factor-responsive precursor from the embryonic ventral forebrain. J Neurosci 24:10888-10899.

Confavreux C, Hutchinson M, Hours MM, Cortinovis-Tourniaire P, Moreau T (1998) Rate of pregnancy-related relapse in multiple sclerosis. Pregnancy in Multiple Sclerosis Group. N Engl J Med 339:285-291.

Dawson MR, Polito A, Levine JM, Reynolds R (2003) NG2-expressing glial progenitor cells: an abundant and widespread population of cycling cells in the adult rat CNS. Mol Cell Neurosci 24:476-488.

Demerens C, Stankoff B, Logak M, Anglade P, Allinquant B, Couraud F, Zalc B, Lubetzki C (1996) Induction of myelination in the central nervous system by electrical activity. Proc Natl Acad Sci USA 93:9887-9892.

Dong WK, Greenough WT (2004) Plasticity of nonneuronal brain tissue: roles in developmental disorders. Ment Retard Dev Disabil Res Rev 10:85-90. 
Draca S, Levic Z (1996) The possible role of prolactin in the immunopathogenesis of multiple sclerosis. Med Hypotheses 47:89-92.

Faulkner J, Keirstead HS (2005) Human embryonic stem cell-derived oligodendrocyte progenitors for the treatment of spinal cord injury. Transpl Immunol 15:131-142.

Ferro JM, Madureira S (2002) Age-related white matter changes and cognitive impairment. J Neurol Sci 203-204:221-225.

Fields RD (2005) Myelination: an overlooked mechanism of synaptic plasticity? The Neuroscientist 11:528-531.

Fleming AS, Walsh C (1994) Neuropsychology of maternal behavior in the rat: c-fos expression during mother-litter interactions. Psychoneuroendocrinology 19:429-443.

Freeman ME, Kanyicska B, Lerant A, Nagy G (2000) Prolactin: structure, function, and regulation of secretion. Physiol Rev 80:1523-1631.

Gatewood JD, Morgan MD, Eaton M, McNamara IM, Stevens LF, Macbeth AH, Meyer EA, Lomas LM, Kozub FJ, Lambert KG, Kinsley CH (2005) Motherhood mitigates aging-related decrements in learning and memory and positively affects brain aging in the rat. Brain Res Bull 66:91-98.

Gensert JM, Goldman JE (1996) In vivo characterization of endogenous proliferating cells in adult rat subcortical white matter. Glia 17:39-51.

Gensert JM, Goldman JE (1997) Endogenous progenitors remyelinate demyelinated axons in the adult CNS. Neuron 19:197-203.

Gur RC, Turetsky BI, Matsui M, Yan M, Bilker W, Hughett P, Gur RE (1999) Sex differences in brain gray and white matter in healthy young adults: correlations with cognitive performance. J Neurosci 19:4065-4072.

Hack MA, Saghatelyan A, de Chevigny A, Pfeifer A, Ashery-Padan R, Lledo PM, Gotz M (2005) Neuronal fate determinants of adult olfactory bulb neurogenesis. Nat Neurosci 8:865-872.

Haier RJ, Jung RE, Yeo RA, Head K, Alkire MT (2005) The neuroanatomy of general intelligence: sex matters. NeuroImage 25:320-327.

Ito A, Bebo Jr BF, Matejuk A, Zamora A, Silverman M, Fyfe-Johnson A, Offner H (2001) Estrogen treatment down-regulates TNF-alpha production and reduces the severity of experimental autoimmune encephalomyelitis in cytokine knockout mice. J Immunol 167:542-552.

Jeffery ND, Blakemore WF (1995) Remyelination of mouse spinal cord axons demyelinated by local injection of lysolecithin. J Neurocytol 24:775-781.

Karimi-Abdolrezaee S, Eftekharpour E, Wang J, Morshead CM, Fehlings MG (2006) Delayed transplantation of adult neural precursor cells promotes remyelination and functional neurological recovery after spinal cord injury. J Neurosci 26:3377-3389.

Keirstead HS, Nistor G, Bernal G, Totoiu M, Cloutier F, Sharp K, Steward O (2005) Human embryonic stem cell-derived oligodendrocyte progenitor cell transplants remyelinate and restore locomotion after spinal cord injury. J Neurosci 25:4694-4705.

Kempermann G, Kuhn HG, Gage FH (1997) More hippocampal neurons in adult mice living in an enriched environment. Nature 386:493-495.

Kim JH, Juraska JM (1997) Sex differences in the development of axon number in the splenium of the rat corpus callosum from postnatal day 15 through 60. Brain Res Dev Brain Res 102:77-85.

Kim S, Liva SM, Dalal MA, Verity MA, Voskuhl RR (1999) Estriol ameliorates autoimmune demyelinating disease: implications for multiple sclerosis. Neurology 52:1230-1238.

Kinsley CH, Madonia L, Gifford GW, Tureski K, Griffin GR, Lowry C, Williams J, Collins J, McLearie H, Lambert KG (1999) Motherhood improves learning and memory. Nature 402:137-138.

Lambert KG, Berry AE, Griffins G, Amory-Meyers E, Madonia-Lomas L, Love G, Kinsley CH (2005) Pup exposure differentially enhances foraging ability in primiparous and nulliparous rats. Physiol Behav 84:799-806.

Larsen PH, Wells JE, Stallcup WB, Opdenakker G, Yong VW (2003) Matrix metalloproteinase- 9 facilitates remyelination in part by processing the inhibitory NG2 proteoglycan. J Neurosci 23:11127-11135.

Lee KH, Yoon DH, Park YG, Lee BH (2005) Effects of glial transplantation on functional recovery following acute spinal cord injury. J Neurotrauma 22:575-589.

Levison SW, Young GM, Goldman JE (1999) Cycling cells in the adult rat neocortex preferentially generate oligodendroglia. J Neurosci Res $57: 435-446$.

Ling C, Hellgren G, Gebre-Medhin M, Dillner K, Wennbo H, Carlsson B, Billig H (2000) Prolactin (PRL) receptor gene expression in mouse adipose tissue: increases during lactation and in PRL-transgenic mice. Endocrinology 141:3564-3572.
Lledo PM, Alonso M, Grubb MS (2006) Adult neurogenesis and functional plasticity in neuronal circuits. Nat Rev Neurosci 7:179-193.

Love G, Torrey N, McNamara I, Morgan M, Banks M, Hester NW, Glasper ER, Devries AC, Kinsley CH, Lambert KG (2005) Maternal experience produces long-lasting behavioral modifications in the rat. Behav Neurosci 119:1084-1096.

Mack CM, Boehm GW, Berrebi AS, Denenberg VH (1995) Sex differences in the distribution of axon types within the genu of the rat corpus callosum. Brain Res 697:152-160.

Mason JL, Langaman C, Morell P, Suzuki K, Matsushima GK (2001) Episodic demyelination and subsequent remyelination within the murine central nervous system: changes in axonal calibre. Neuropathol Appl Neurobiol 27:50-58.

Menn B, Garcia-Verdugo JM, Yaschine C, Gonzalez-Perez O, Rowitch D, Alvarez-Buylla A (2006) Origin of oligodendrocytes in the subventricular zone of the adult brain. J Neurosci 26:7907-7918.

Mirescu C, Gould E (2006) Stress and adult neurogenesis. Hippocampus 16:233-238.

Mori E (2002) Impact of subcortical ischemic lesions on behavior and cognition. Ann NY Acad Sci 977:141-148.

Nait-Oumesmar B, Decker L, Lachapelle F, Avellana-Adalid V, Bachelin C, Van Evercooren AB (1999) Progenitor cells of the adult mouse subventricular zone proliferate, migrate and differentiate into oligodendrocytes after demyelination. Eur J Neurosci 11:4357-4366.

Neumann ID (2001) Alterations in behavioral and neuroendocrine stress coping strategies in pregnant, parturient and lactating rats. Prog Brain Res 133:143-152.

Nilsson M, Perfilieva E, Johansson U, Orwar O, Eriksson PS (1999) Enriched environment increases neurogenesis in the adult rat dentate gyrus and improves spatial memory. J Neurobiol 39:569-578.

Nunez JL, Nelson J, Pych JC, Kim JH, Juraska JM (2000) Myelination in the splenium of the corpus callosum in adult male and female rats. Brain Res Dev Brain Res 120:87-90.

Ormandy CJ, Camus A, Barra J, Damotte D, Lucas B, Buteau H, Edery M, Brousse N, Babinet C, Binart N, Kelly PA (1997) Null mutation of the prolactin receptor gene produces multiple reproductive defects in the mouse. Genes Dev 11:167-178.

Peters A, Sethares C (2004) Oligodendrocytes, their progenitors and other neuroglial cells in the aging primate cerebral cortex. Cereb Cortex 14:995-1007.

Picard-Riera N, Decker L, Delarasse C, Goude K, Nait-Oumesmar B, Liblau R, Pham-Dinh D, Evercooren AB (2002) Experimental autoimmune encephalomyelitis mobilizes neural progenitors from the subventricular zone to undergo oligodendrogenesis in adult mice. Proc Natl Acad Sci USA 99:13211-13216.

Polito A, Reynolds R (2005) NG2-expressing cells as oligodendrocyte progenitors in the normal and demyelinated adult central nervous system. J Anat 207:707-716.

Rochefort C, Gheusi G, Vincent JD, Lledo PM (2002) Enriched odor exposure increases the number of newborn neurons in the adult olfactory bulb and improves odor memory. J Neurosci 22:2679-2689.

Schradin C, Anzenberger G (1999) Prolactin, the hormone of paternity. News Physiol Sci 14:223-231.

Scolding NJ, Franklin RJ (1997) Remyelination in demyelinating disease. Baillieres Clin Neurol 6:525-548.

Shingo T, Gregg C, Enwere E, Fujikawa H, Hassam R, Geary C, Cross JC, Weiss S (2003) Pregnancy-stimulated neurogenesis in the adult female forebrain mediated by prolactin. Science 299:117-120.

Sicotte NL, Liva SM, Klutch R, Pfeiffer P, Bouvier S, Odesa S, Wu TC, Voskuhl RR (2002) Treatment of multiple sclerosis with the pregnancy hormone estriol. Ann Neurol 52:421-428.

Sirevaag AM, Greenough WT (1987) Differential rearing effects on rat visual cortex synapses. III. Neuronal and glial nuclei, boutons, dendrites, and capillaries. Brain Res 424:320-332.

Stevens B, Porta S, Haak LL, Gallo V, Fields RD (2002) Adenosine: a neuron-glial transmitter promoting myelination in the CNS in response to action potentials. Neuron 36:855-868.

Sturrock RR (1980) Myelination of the mouse corpus callosum. Neuropathol Appl Neurobiol 6:415-420.

Szeligo F, Leblond CP (1977) Response of the three main types of glial cells of cortex and corpus callosum in rats handled during suckling or exposed 
to enriched, control and impoverished environments following weaning. J Comp Neurol 172:247-263.

Tang DG, Tokumoto YM, Raff MC (2000) Long-term culture of purified postnatal oligodendrocyte precursor cells. Evidence for an intrinsic maturation program that plays out over months. J Cell Biol 148:971-984.

Tauber H, Waehneldt TV, Neuhoff V (1980) Myelination in rabbit optic nerves is accelerated by artificial eye opening. Neurosci Lett 16:235-238.

Totoiu MO, Keirstead HS (2005) Spinal cord injury is accompanied by chronic progressive demyelination. J Comp Neurol 486:373-383.

van Praag H, Kempermann G, Gage FH (1999) Running increases cell proliferation and neurogenesis in the adult mouse dentate gyrus. Nat Neurosci 2:266-270. van Walderveen MA, Tas MW, Barkhof F, Polman CH, Frequin ST, Hommes OR, Valk J (1994) Magnetic resonance evaluation of disease activity during pregnancy in multiple sclerosis. Neurology 44:327-329.

Voskuhl RR (2003) Hormone-based therapies in MS. Int MS J 10:60-66.

Walker CD, Deschamps S, Proulx K, Tu M, Salzman C, Woodside B, Lupien S, Gallo-Payet N, Richard D (2004) Mother to infant or infant to mother? Reciprocal regulation of responsiveness to stress in rodents and the implications for humans. J Psychiatry Neurosci 29:364-382.

Weetman AP (1999) The immunology of pregnancy. Thyroid 9:643-646.

Wu HY, Dawson MR, Reynolds R, Hardy RJ (2001) Expression of QKI proteins and MAP1B identifies actively myelinating oligodendrocytes in adult rat brain. Mol Cell Neurosci 17:292-302. 